\title{
浅析园林绿化档案存在的问题及基本对策
}

\author{
吴艳萍 \\ 江苏省盐城市射阳县园林绿化管理局 \\ DOI:10.32629/ej.v2i6.319
}

[摘 要] 城市现代化建设进程持续加快,园林绿化工程规模进一步扩大,在改善城市环境,维护生态系统平衡方面具有积极作用。为了指导园林 绿化工程建设活动有序展开, 做好园林绿化档案工作十分重要。但是, 当前园林绿化档案中存在一系列问题, 档案管理意识薄弱, 配套的制度和体 系不健全,严重影响到园林绿化档案工作成效。本文就园林绿化档案中的问题进行分析,提出可行的改进措施,打造高质量的园林绿化工程。

[关键词] 园林绿化工程; 档案管理; 管理体制; 管理意识

在园林绿化事业持续发展下, 大量资金投入其中, 促使园林绿化取得 了可观的成果。在园林绿化工程建设中, 园林绿化档案对于整体规划和建 设具有重要指导作用, 可以规避重复投资问题出现, 提升园林绿化档案工 作效率。以往的园林绿化档案工作存在很多不足, 极大的影响到园林绿化 档案资料潜在价值挖掘和利用, 应进一步改进和创新, 全面提升园林绿化 档案工作成效。

\section{1 园林绿化档案的重要作用}

在城市现代化建设中, 园林绿化规模不断扩大, 做好园林绿化档案具 有积极作用。园林绿化档案是绿化建设工作中的主要依据, 在园林绿化设 计和建设中, 通过整合相关资料来推广科技成果, 切实提升园林绿化工 程建设效果。在园林绿化档案中, 记录了园林绿化数据, 以档案为依据进 行园林绿化档案管理, 有助于合理配置资源, 最大程度上降低人力、物力 和财力 ${ }^{[1]}$ 。园林绿化工程的规划和建设, 离不开园林绿化档案的支持, 有助 于带来可观的经济效益和社会效益。

园林绿化档案有以下几个特点：（1）专业性。园林绿化档案相较于一 般档案资料, 是园林绿化生产活动和科技创新的相关记录。(2)成套性。园 林绿化档案记录了园林绿化工程的设计、施工、维护全过程资料, 客观反 映园林绿化的建设情况, 各个环节紧密联系, 形成完整的档案体系。(3)动 态性。园林绿化档案具有动态性特点, 随着工程进展园林绿化档案数量和 内容动态变化, 以此来满足园林绿化工程需要。

\section{2 园林绿化档案中的问题分析}

2. 1 园林绿化档案管理意识薄弱

在园林绿化档案工作开展中, 一个主要问题则是园林绿化档案管理意 识薄弱, 未能正确认识到园林绿化档案重要性。相关市政部门对园林绿化 档案认知不足, 相关部门的职能发挥不充分, 影响到园林绿化档案资料的 高效利用, 阻碍后续相关工作顺利开展。部分新建的园林绿化工程和道路 工程施工中, 配套的档案资料未能及时移交, 缺少专门的人员负责档案管 理, 留下了一系列问题, 影响到园林绿化档案管理工作成效 ${ }^{[2]}$ 。

\section{2 园林绿化档案配套体制不健全}

在园林绿化施工中, 工程的投资、建设和管理涉及到众多部门, 档案资 料总量较大, 需要收集、归档和保管, 环节众多, 而园林绿化档案资料难以 实现统一管理, 存在很大的不足。园林绿化工程建设后, 部门未能及时归档 和保管档案, 可能导致档案资料丢失, 影响到园林绿化档案原有价值挖掘 和利用 ${ }^{[3]}$ 。档案资金投入力度多少, 很大程度上影响到后续工作的顺利展 开, 但是部分单位的园林绿化档案资金投入力度不足, 配套的设备陈旧、滞 后, 信息化水平不高, 甚至并未设立专门的园林绿化档案档案室, 极大的影 响园林绿化档案工作成效 ${ }^{[4]}$ 。

2. 3 档案资料不完整
园林绿化档案涉及到众多内容, 如何保证档案资料完整性, 需要做好 档案资料的收集、保管和利用。园林绿化工程建设周期长, 其中包括很多 实际性的文件资料, 以及设计文件、前期文件和监理文件, 但是部分单位未 能收集施工工艺和隐蔽工程资料。由于资料缺失, 影响到后续的园林绿化 档案管理成效, 带来不同程度的损失。另外, 园林绿化档案信息化水平不高, 园林绿化档案收集、整理、保管流程僵硬, 部分人员认为只需要保管关键 资料即可, 致使档案资料管理信息化水平不高 ${ }^{[5]}$ 。

\section{3 园林绿化档案的管理措施}

针对当前园林绿化档案中的问题, 如何实现档案资料潜在价值深入挖 掘和利用, 应提出合理有效的措施予以实践, 落实到实处。

3. 1 提升对园林绿化档案的重视

如何有效改善园林绿化档案中的问题, 应该顺应社会发展趋势, 加深 园林绿化档案认知和重视, 深入挖掘园林绿化档案潜在价值, 为后续的城 市规划和建设提供可靠依据。为了可以在激烈市场竞争中占据优势, 园林 绿化建设单位应增加园林绿化档案资金投入力度, 明确园林绿化档案管理 的重要性, 以便于按照相应制度及时收集和整理档案资料, 在此基础上不 断创新, 确保后续的园林绿化施工活动有序进行, 对于企业健康出现发展 意义深远。

3.2 建立完善的园林绿化档案管理制度

为了保证园林绿化档案管理工作有序展开, 应结合实际情况, 明确园 林绿化档案重要性基础上制定完善的管理制度和体系, 推动园林绿化档案 规范化展开。制定明确的档案管理标准和流程, 依据制度规范化进行档 案收集、保管、鉴定和利用, 为档案质量提供保障。将不同档案类别集 中统一管理, 实现档案资料及时归档和保管, 各个环节得到全面监管和 控制 ${ }^{[6]}$ 。同时, 加强制度考核, 将制度纳入到岗位考核体系范畴, 强化档案 管理部门职能, 提升人员的档案遗失, 以便于实现档案动态化管理, 保证档 案资料完整性。

3. 3推动园林绿化档案信息化建设

在信息时代背景下, 为了全面提升园林绿化档案工作水平, 应该增加 资金投入力度, 持续推动园林绿化档案信息化建设。迎合新时期发展需要, 正确看待园林绿化档案重要性, 设立专门的档案室, 实现各个部门档案资 料的集中统一管理, 保证档案管理符合标准要求, 推动园林绿化档案升级 改造。提升园林绿化档案信息化水平,相较于传统的档案管理模式优势更 为突出, 可以降低人工劳动强度, 加快信息化步伐, 借助前沿的信息技术高 效存储和利用。纸质档案和电子档案兼顾保管, 推动园林绿化档案工作持 续发展。

3. 4加强园林绿化档案管理人员的专业培训

相关部门应定期组织园林绿化档案管理人员参加专业培训, 明确时代 


\title{
新形势背景下档案管理方面现代化的有效途径
}

\author{
崔向国
}

洮南市财政局

DOI:10.32629/ej.v2i6.278

[ 摘 要] 在新阶段的社会背景之下,很多行政事业单位以及行政事业单位的档案管理工作模式也发生了很大的变化,对于档案管理工作的整体 水平有了更高的要求。对于传统的档案管理工作方式来说, 在实际应用的过程中往往会受到多种因素的影响,从而导致了档案管理的综合效率并 不高,这在一定程度上影响到了行政事业单位以及行政事业单位的正常运行管理。在现阶段新的社会背景之下,档案管理工作也应该积极与现代 化的运行模式进行结合,对传统档案管理中的不足之处进行积极弥补。

[关键词] 新形势下; 档案管理; 现代化; 有效途径

随着我国社会现代化发展水平的不断提升, 信息技术已经得到了广泛 的应用, 对我国多个传统行业的发展都起到了很大的促进作用。自从有了 计算机技术之后, 我国的社会经济发展已经进入到了一个新的阶段。在这 样的时代背景之下, 行政事业单位的传统档案管理方式已经很难满足现阶 段工作展开的实际需求了。尤其是对于市级的行政事业单位而言, 其工作 内容具有多样化的特点, 由于工作内容较为庞杂, 日常所涉及到的档案种 类也会更多,传统的档案管理方式在实际应用的过程中很难保证归档以及 档案管理的综合效率以及质量, 经常会出现档案分类不准确的情况。因此, 为了更好的满足现阶段社会以及行业的实际运转需求应该全面落实应用 现代化的档案管理理念。

\section{1 档案管理现代化的重要意义}

对于档案管理工作来说, 在实际展开的过程中应该注意对现阶段行政 事业单位以及行政事业单位自身的岗位职责、工作内容进行明确。随着我 国社会的不断进步, 很大一部分事业单位都已经进入到了现代化办公以及 发展的阶段。因此, 对于档案管理工作来说, 在实际展开的过程中, 也应该 积极与现代化的办公管理理念进行结合。对于行政事业单位的档案管理工 作来说, 在实际展开的过程中应该注意对以下几个方面进行考虑。首先在 展开档案管理的时候, 应该充分考虑到纸质档案会出现模糊的情况 ${ }^{[1]}$ 。此 外, 对于传统的档案历方式来说, 在进行档案查阅的时候, 可能会出现档案 损坏以及档案丢失的情况。例如, 在对档案进行交通运输的时候, 必然会涉 及到对档案的搬运, 在这样的过程中很容易出现档案丢失以及损坏的情 况。尤其现阶段我部门的档案数量正在逐渐增加, 如果还是应用传统的管 理方式势必会导致其综合管理效果受到很大的影响。

\section{2 现阶段现代化档案管理过程中存在的问题}

发展趋势, 帮助档案管理人员不断学习前沿知识和技能, 熟练运用现代化 技术和手段辅助园林绿化档案工作开展。强化档案管理人员职业道德教育 培训, 各个部门沟通和交流, 可以熟练运用现代化信息技术和手段, 提升园 林绿化档案的信息化水平。在高素质的园林绿化档案工作队伍支持下, 促 使园林绿化档案工作有序展开, 切实提升园林绿化档案工作效率和质量。

\section{4 结论}

综上所述, 城市园林绿化工程规模不断扩大, 档案资料总量大幅度增 加, 面对新时期档案事业发展要求, 应该正确看待园林绿化档案工作重要 性, 增加资金投入力度。推动园林绿化档案技术和方法创新, 制定完善的制 度和体系, 在高素质的园林绿化档案管理人员支持下, 优化园林绿化档案 管理流程, 提升园林绿化档案工作成效。

[参考文献]
2. 1 对于档案管理工作的认知不到位

对于一部分在职的档案管理工作人员来说, 往往对档案管理工作的认 知存在不到位的情况, 这与其从事档案管理工作的时间不长有直接关系, 往往认为档案管理工作只是对档案进行简单的记录以及分类, 这种认知是 错误的, 这也在很大程度上导致档案管理工作在实际展开的过程中具有一 定随意性。

2. 2 档案管理过程存在不规范的情况

对于档案管理工作来说明, 对其进行细分之后, 可以将其分为档案采 集、档案整理、档案分类、档案保存以及档案查阅等等几个部分。但是从 现阶段我国档案管理工作展开的实际情况来看, 档案管理的过程存在着不 规范的情况。在新的时代背景之下, 不仅要保证档案管理工作的整体严谨 性, 同时还应该保证档案管理工作可与现阶段社会以及行业发展的实际情 况相符合。由于我国现阶段的档案管理制度还存在着不够完善的情况, 同 时, 也不能够有效实现各部门的积极沟通, 一旦在档案管理工作展开的过 程中出现了问题, 很难在第一时间解决。

\section{3 提高档案管理现代化水平的有效策略}

3. 1 积极利用现代化档案管理技术促进各部门之间的交流沟通

对于行政事业单位的档案管理工作来说, 在实际展开的过程中经常会 涉及到一些问题, 需要多各部门之间进行沟通以及商议之后才能解决。从 现阶段我国很多单位的档案管理工作展开情况来看, 档案管理部门往往是 单独存在的, 这样一来可能会导致各个部门之间的交流以及沟通出现不及 时的情况, 从而导致了相关问题不能够得到及时有效的解决 ${ }^{[2]}$ 。同时, 在档 案管理工作展开的过程中, 还会经常涉及到信息以及材料的调用, 如果依 靠现代化技术可以及时向信息部门提供信息检索权,这样一来也就使得档

[1]宫冬艳.探析加强城市园林绿化工程档案管理工作的策略[J].办公 室业务,2018,23(14):126.

[2]郭媇.分析市政工程影响下园林绿化的档案管理与保护[J].办公室 业务,2018,31(13):96.

[3]杜虹云.园林绿化档案管理在宜居城市建设中的意义研究[J].企业 改革与管理,2015,19(16):222.

[4]姜东昕.加强园林科研档案管理为城市园林绿化建设服务[J].办公 室业务,2014,21(11):188-189.

[5]江毓亮. 从园林绿化档案看城市居住绿化环境建设的弊端[J].城建 档案,2013,23(09):9-10.

[6]马红岩, 苗满田.毫州市完善园林绿化档案积极创建省级园林城市 [J].山东档案,2013,14(01):53. 